\title{
Configuring Green Infrastructure for Urban Runoff and Pollutant Reduction Using an Optimal Number of Units
}

\author{
Carlos Martínez ${ }^{1,2, *(\mathbb{D}}$, Arlex Sanchez ${ }^{2}$, Roberto Galindo ${ }^{2}$, Aelaf Mulugeta ${ }^{2}$, Zoran Vojinovic ${ }^{2}$ \\ and Alberto Galvis ${ }^{3}$ (D) \\ 1 Universidad del Magdalena, Program of Civil Engineering, Carrera 32 No. 22-08, \\ Santa Marta 470002, Colombia \\ 2 Environmental Engineering and Water Technology Department, IHE-Delft Institute for Water Education, \\ Westvest 7, 2611 AX Delft, The Netherlands; a.sanchez@un-ihe.org (A.S.); glc.roberto@gmail.com (R.G.); \\ aluv07@gmail.com (A.M.); z.vojinovic@un-ihe.org (Z.V.) \\ 3 Cinara Institute, Faculty of Engineering, Universidad Del Valle Calle 13 N ${ }^{\circ}$ 100-00, Building 341, \\ Cali 76001, Colombia; alberto.galvis@correounivalle.edu.co \\ * Correspondence: cmartinez@unimagdalena.edu.co; Tel.: +57-5-4217940 (ext. 2291)
}

Received: 8 August 2018; Accepted: 15 October 2018; Published: 26 October 2018

\begin{abstract}
Green infrastructure (GI) has been regarded as an effective intervention for urban runoff reduction. Despite the growing interest in GI, the technical knowledge that is needed to demonstrate their advantages, cost, and performance in reducing runoff and pollutants is still under research. The present paper describes a framework that aims to obtain the optimal configuration of GI (i.e., the optimal number of units distributed within the catchment) for urban runoff reduction. The research includes an assessment of the performance of GI measures dealing with pollution load, peak runoff, and flood volume reduction. The methodological framework developed includes: (1) data input, (2) GI selection and placement, (3) hydraulic and water quality modelling, and (4) assessing optimal GI measures. The framework was applied in a highly urbanized catchment in Cali, Colombia. The results suggest that if the type of GI measure and its number of units are taken into account within the optimisation process, it is possible to achieve optimal solutions to reduce the proposed reduction objectives with a lower investment cost. In addition, the results also indicate a pollution load, peak runoff, and flood volume reduction for different return periods of at least 33\%, $28 \%$, and $60 \%$, respectively. This approach could assist water managers and their stakeholders to assess the trade-offs between different GI.
\end{abstract}

Keywords: green infrastructure; hydrodynamic modelling; multi-objective optimisation; urban drainage

\section{Introduction}

There is a growing interest in urban runoff processes, since more than half of the world's population live in urban areas. As a result, urban water researchers and practitioners are increasingly concerned with how to manage urban runoff with the effort to maintain more water on-site and to replicate natural hydrological processes. Urban runoff is generated when rainfall flows over land or impervious surfaces, such as paved streets, parking lots, and rooftops and does not seep into the ground. Apart from direct damage, heavy rainfall can also lead to a sequence of cascading events, such as power interruptions, traffic congestion, business interruptions, and pollution of water bodies [1].

In the past, the urban runoff control was focused on efficient surface drainage and flood control for a given return period rainfall event that was often of a larger magnitude [2]. However, researchers and practitioners are becoming increasingly concerned with the runoff resulting from smaller and more 
frequently occurring rainfall events that can cause a sequence of negative effects in urban areas and receiving waters [3].

The main pollutants found in runoff come from fertilizers (nutrients), humans and animals (bacteria), chemicals (pesticides), roofs and roads (metals), and from vehicles (hydrocarbons) [4]. Suspended sediments constitute the largest mass of pollutant loadings to receiving waters from urban areas and is generally conveyed by urban drainage as non-point pollution [5]. Polluted urban drainage runoff can be harmful to plants, animals, and people, and its quality was largely ignored in the design of urban drainage systems until approximately 1980 [6].

Green Infrastructure (GI) is an attractive option for urban water managers as it has the potential to provide a range of benefits and co-benefits. If carefully designed and implemented, GI can be effective in dealing with problems associated with floods and droughts as well as with poor urban runoff quality $[7,8]$. However, retrofitting GIs in long-established urban areas can be a technically very challenging and costly task [9]. Previous studies aiming to evaluate the performance of GI in urban water systems have been carried out by: (i) modelling tools for stormwater management and the economics of GI practices [10], (ii) evaluating the importance of GI in small and medium-sized towns [11], (iii) examining the performance of vegetative swales to improve runoff in an urban area with moderate traffic [12], (iv) proposing a flexible modelling framework for hydraulic and water quality performance assessment of stormwater GI [13], (v) combining ecosystem services with a cost-benefit analysis for the selection of green and grey infrastructure for flood protection in a cultural heritage [14], and (vi) combining co-benefits and stakeholders' perceptions into the GI selection for flood risk reduction [15]. The results from these studies have shown good potential for application of GI in urban water management.

Numerical models have proved to be invaluable for modelling flows in urban areas [16,17], while multi-objective optimisation can provide useful support in decision-making processes. In addition, the combination of numerical models and optimisation tools, such as the NSGA-II optimiser has proved to be particularly useful for dealing with stormwater-related issues [18-20]. The objective of the NSGA-II algorithm is to improve the adaptive fit of a population of candidate solutions to a Pareto front that is constrained by a set of objective functions. The algorithm uses an evolutionary process with surrogates for evolutionary operators, including selection, genetic crossover, and genetic mutation. The population is sorted into a hierarchy of sub-populations that is based on the ordering of Pareto dominance. Similarity between members of each sub-group is evaluated on the Pareto front, and the resulting groups and similarity measures are used to promote a diverse front of non-dominated solutions [21].

Investigations where NSGA-II have been used to optimise GI have focused on: (i) multiobjective optimisation for combined quality-quantity urban runoff control [22], (ii) selecting an optimal sustainable drainage design for urban runoff reduction [23], and (iii) proposing an evolutionary and holistic assessment of green-grey infrastructure for CSO reduction [24]. Other multiobjective evolutionary algorithms are also used to optimise GI, as in the case of (iv) minimization of cost, sediment load, and sensitivity to climate change in a watershed management application [25], (v) optimal selection and placement of green infrastructure to reduce the impacts of land use change and climate change on hydrology and water quality [26], (vi) optimal sizing of GI treatment trains (i.e., a sequence of multiple stormwater treatments) for stormwater management [27], and (vii) a quantitative modelling framework to support decision making in Sustainable urban Drainage Systems (SuDS) design alternatives [28]. The above approaches have produced promising results and may become a useful tool for planning and decision making of drainage systems.

Based on the previous studies, the benefits of applying GI measures (or practices) are well known. However, currently available methodologies are more focused on the optimal coverage area of GI instead of a GI-type preference. The key advantage of the present approach is that the number of equal GI-size units redistributed within the subcatchment has been taken into account within the optimisation process and this is presented in more detail in the subsequent sections. 
The present paper provides a novel approach that aims to configure GI for urban runoff and pollutant reduction using the optimal number of units. The research includes an assessment of the performance of GI measures when dealing with two main objectives: environmental (i.e., pollution load, peak runoff, flood volume) and economic (i.e., investment costs). This proposed framework has been implemented in the coding environment LAZARUS (a free source Delphi compatible with cross-platform IDE for rapid application development) in order to couple a hydrodynamic model with an optimisation algorithm. This coupled model searches for optimal GI units that can achieve runoff reduction, better runoff quality, and least investment costs. The potential of this method has been demonstrated in the real-life case study of Cali, Colombia, where different GI units were evaluated while considering the environmental and economic objectives.

\section{Case Study}

An urban area within the Meléndez catchment in Cali (Colombia) has been used to demonstrate the proposed framework. The catchment area encompasses $46.2 \mathrm{~km}^{2}$ and the river network has a length of $7 \mathrm{~km}$, which receives discharges from both sewer pipes and open channels. Since the 1990s, there have been floods and pollution due to river overflows along its entire length that have affected highly urbanized sectors. The area that is divided into the south and southwest has a higher population density. The total area can be delineated into 25 subcatchments, and the drainage system is formed by one river, 22 open channel sections, 21 box culvers, and 51 circular pipes. The surface runoff flows by gravity from west to east of the catchment to reach the outfall in the southern channel. According to [29], the estimated time of concentration is approximately $84 \mathrm{~min}$. The urban catchment has one outflow point near to the Cauca river, which is the main source of drinking water for Cali. The river receives an average discharge of $0.51 \mathrm{~m}^{3} / \mathrm{s}$ per day from the Meléndez catchment [30]. Figure 1 shows the urban drainage catchment of the study area.

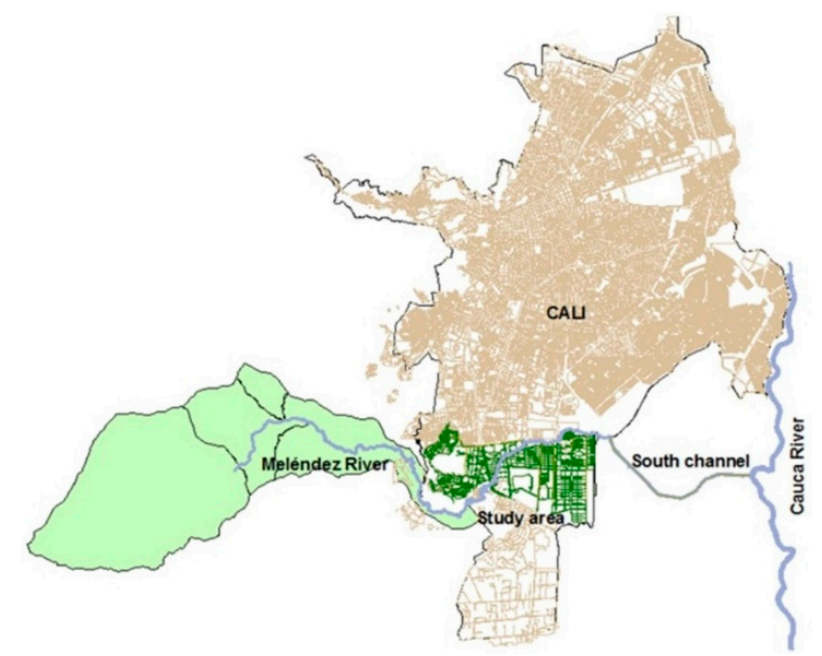

Figure 1. Location of the Meléndez catchment area within the city of Cali.

\section{Methodological Framework}

The methodological framework for optimal system configuration of GIs consists of four main steps: (1) data input, (2) GI selection and placement, (3) hydraulic and water quality modelling, and (4) assessing optimal GI measures. These steps are described in detail in the following subsections.

\subsection{Data Input}

The data used in this study includes the network layout, conduits, canals, manholes, outflow, and subcatchments with their hydrological parameters and dry weather flow characteristics. Subcatchment parameters include outlet nodes, percentages of previous and impervious areas, 
terrain slope, depression storage, and soil infiltration characteristics. The present work also used contour maps, a Digital Elevation Model (DEM), land use, the percentage of impervious areas, soil type, urban land use, roads, streams, the groundwater table depth, and land ownership. Rainfall is introduced into the model with hyetographs for 2, 5, 10, 20, and 50-year return period events based on intensity, duration, and frequency. Water quality data obtained from the DAGMA project [31] was used for build-up and wash-off model simulations.

Figure 2a depicts the geographical location of the monitoring points. Point 1 was selected as a reference point in order to determine the status of the water quality of the river before it reaches the urban area. Two stations were taken into account in the rural area (i.e., points 2 and 3) with the purpose of evaluating the impact from coal mines. In total, 10 monitoring points were monitored to evaluate the water quality of the river. The maximum daily Total Suspended Solids (TSS) measured was approximately $6500 \mathrm{~kg}$ /day and a minimum Dissolved Oxygen (DO) of $2 \mathrm{mg} / \mathrm{L}$ (see Figure 2b).

In order to represent the TSS loads for each subcatchment for a 10-year return period and for validation of the model purposes, different input concentrations were specified at different nodes of the drainage network by a trial-and-error procedure in accordance with the data reported in $[32,33]$. TSS was also introduced into the model at specific nodes representing the combined sewer in the conveyance system. This makes it possible to represent the pollutant concentration coming from the dry weather flow-DWF (i.e., assumed DWF diurnal pattern). After assigning different TSS concentrations into the system, the modelled Meléndez river produced a TSS-based flow concentration of $10 \mathrm{mg} / \mathrm{L}$ comparable to the TSS profile measured and presented in Figure 2c. This value was placed as a boundary condition in the model.

In terms of the costs concerning different GI measures, a catalogue with different costs was compiled. This catalogue contains unit costs for different GI types (see the summary table of GI in Appendix A).

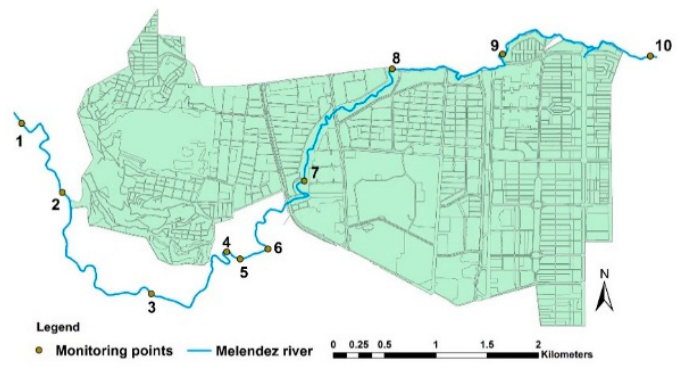

(a) Water quality monitoring points

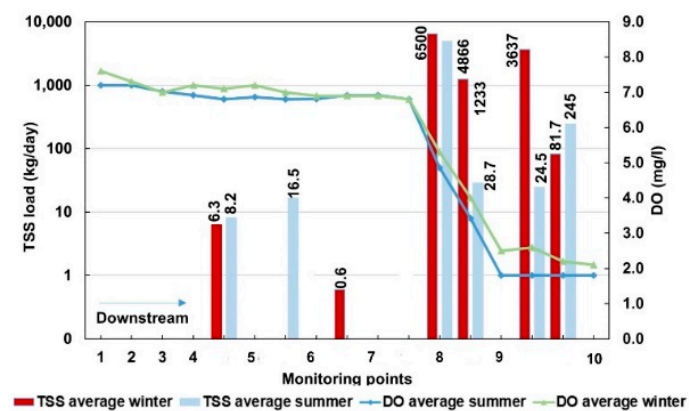

(b) Measured Total Suspended Solids (TSS) (kg/day) and Dissolved Oxygen (DO) $(\mathrm{mg} / \mathrm{L})$

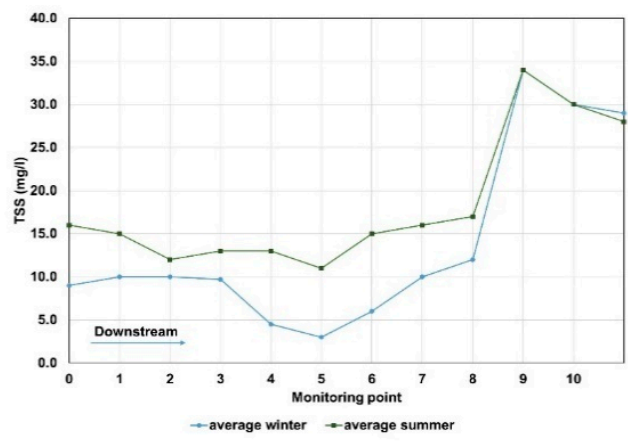

(c) TSS concentration profile

Figure 2. Water quality data in the Meléndez river source: [34]. 


\subsection{GI Selection and Placement}

\subsubsection{GI Selection}

The different GIs were selected based on their characteristics and suitability for implementation in the urban area. The selection is based on the requirements concerning land use, applicability on the impervious area, and treatment capacity. The GIs were implemented within each subcatchment by defining the number of units and surface area for each type. The selected GI includes Bio-Retention cells (BR) for expanding the green space in the subcatchments, Infiltration Trenches (IT) for using around playing fields and recreational areas, Porous Pavement (PP) to reduce storm water runoff, and Vegetative Swales (VS) with the purpose of improving the water quality.

Table 1 presents the characteristics of the GI design following the recommended values given in [34]. The BR were selected with the minimum recommended dimensions (4.6 m wide by $12.2 \mathrm{~m}$ in length). The minimum width allows the BR to control the effects of runoff pollutants while the minimum length enables the cell to accommodate the distributed flow by decreasing the changes of concentrated flow. The ponding depth was set to 120 millimetres to give a sufficient water storage capacity and a vegetative fraction was set to 0.05. Three types of BR (BR01, BR02, and BR03) were used according to the soil characteristics and either to drain out by infiltration or underdrains. Two types of IT (IT01 and IT02) were used to cover from 2 to 4 ha drainage area, draining within $24 \mathrm{~h}$, and with a storage depth of $1400 \mathrm{~mm}$. The seepage rate was set depending on the soil class. PP (PP01) was chosen to infiltrate water through the soil so that there is no vegetative cover on top. vs. (VS01) was also selected based on the two year-return period with high vegetative cover. The swale side slope was set to be $5 \%$ and covered by dense vegetation, usually grass, to slow down flows and to trap pollutants [35]. Appendix A presents a summary table with the detailed information of the selected GI.

Table 1. Characteristics of the Green Infrastructure (GI) design (configuration parameters).

\begin{tabular}{|c|c|c|c|c|c|c|c|c|c|}
\hline Layer & Property & Units & BR01 & BR02 & BR03 & IT01 & IT02 & VS01 & PP01 \\
\hline \multirow{4}{*}{ Surface } & Berm height & $\mathrm{mm}$ & 120 & 120 & 120 & 200 & 200 & 900 & 5 \\
\hline & Vegetation volume & fraction & 0.05 & 0.05 & 0.05 & 0 & 0 & 0.15 & 0 \\
\hline & Surface roughness & Manning $\mathrm{n}$ & 0 & 0.001 & 0.001 & 0.25 & 0.25 & 0.40 & 0.012 \\
\hline & Surface slope & & 0 & 0.5 & 0.5 & 0.5 & 0.5 & 2 & 1 \\
\hline \multirow{8}{*}{ Soil } & Swale side slope & (run/rise) & & & & & & 5 & \\
\hline & Thickness & $\mathrm{mm}$ & 800 & 900 & 600 & - & - & - & 0 \\
\hline & Porosity & Volume fraction & 0.453 & 0.453 & 0.43 & - & - & - & 0.5 \\
\hline & Field capacity & Volume fraction & 0.212 & 0.144 & 0.1 & - & - & - & 0.2 \\
\hline & Wilting point & Volume fraction & 0.109 & 0.058 & 0.047 & - & - & - & 0.1 \\
\hline & Conductivity & $\mathrm{mm} / \mathrm{h}$ & 14.54 & 3.42 & 2.7 & - & - & - & 0.5 \\
\hline & Conductivity slope & & 7 & 7 & 5 & - & - & - & 10 \\
\hline & Suction head & $\mathrm{mm}$ & 4.33 & 4 & 2 & - & - & - & 3.5 \\
\hline \multirow{4}{*}{ Storage } & Thickness & $\mathrm{mm}$ & 800 & 300 & 300 & 1400 & 1400 & - & 150 \\
\hline & Void ratio & Voids/solids & 0.47 & 0.75 & 0.75 & 0.47 & 0.47 & - & 0.47 \\
\hline & Seepage rate & $\mathrm{mm} / \mathrm{h}$ & 7.27 & 18.79 & 0 & 7.27 & 18.79 & - & 18.79 \\
\hline & Clogging factor & & 0 & 0 & 0 & 0 & 0 & - & 0 \\
\hline \multirow{3}{*}{ Drain } & Flow coefficient & $\mathrm{mm} / \mathrm{h}$ & 0 & 0 & 2.66 & 0 & 0 & - & 1.02 \\
\hline & Flow exponent & fraction & 0.5 & 0 & 0.5 & 0 & 0 & - & 0.5 \\
\hline & Offset height & $\mathrm{mm}$ & 6 & 0 & 50 & 0 & 0 & - & 10 \\
\hline \multirow{5}{*}{ Pavement } & Thickness & $\mathrm{mm}$ & - & - & - & - & - & - & 150 \\
\hline & Void ratio & Voids/solids & - & - & - & - & - & - & 0.15 \\
\hline & Impervious Surf. & Fraction & - & - & - & - & - & - & 0 \\
\hline & Permeability & $\mathrm{mm} / \mathrm{h}$ & - & - & - & - & - & - & 3400 \\
\hline & Clogging factor & & - & - & - & - & - & - & 0 \\
\hline
\end{tabular}

\subsubsection{GI Placement}

Suitable locations for GI placement were obtained by using the best management practices tool, i.e., Siting tool [34]. This tool identifies potential suitable locations/areas for implementing all types of GIs proposed. It supports users with selecting suitable locations that meet the defined site by considering urban land use, location of streams, soil classification, land ownership, and impervious layers. The Siting tool does not consider other constraints such as geological appearance, or the 
socio-economic or political situation. The main output from this tool is the identification of suitable locations for different GIs. A free space was then computed by deducting the land use area coverage from the total area of each subcatchment.

The placement of the GIs was carried out by finding the available space for the implementation of the GI in each subcatchment. The ArcGIS tool was used to define the available area for GI implementation. Subcatchment parameters, such as imperviousness and width, were corrected by using the Equations (1) and (2) [36]:

$$
\begin{aligned}
I m p_{\text {new }} & =\frac{\% \mathrm{Imp} * \text { subcatchment area after GI }}{\text { Total subcatchment area }} \\
W_{\text {new }} & =\frac{\text { subcatchment area after } \mathrm{GI}}{\text { Total subcatchment area }} * W
\end{aligned}
$$

where, Imp new is the new impervious percentage and $W_{\text {new }}$ is the new width of the subcatchments after GI placement. The subcatchment area after GI is determined by having the total area of each subcatchment minus the total area occupied by GIs [36]. As a result of this process, 63 GI types were placed throughout the catchment area and user later as decision variables in the optimisation procedure (see the summary table of GI in Appendix A).

\subsection{Hydraulic and Water Quality Modelling}

The next step involved setting up a hydrodynamic model to simulate quantity and quality as well as the hydrologic and hydraulic routing of urban runoff. This was done in the Storm Water Management Model (SWMM). SWMM solves the Saint-Venant equations that govern the unsteady flow of water through a drainage network of channels and pipes by converting the equations into an explicit set of finite-difference equations [36]. The quantity model calibration was originally undertaken in the studies of $[37,38]$. The mass of a pollutant transported during a storm event has also been modelled in SWMM as a coupled build-up and wash-off process providing stormwater pollutant load that is generated from the urban catchment. In the present work, build-up was computed using Equation (3) in order to describe pollutant build-up over time [35].

$$
b=\operatorname{Min}\left(B_{\max }, K_{B} t^{N_{B}}\right)
$$

where, $b$ is the pollutant build-up $\left(\mathrm{kg} \mathrm{m}^{-1}\right), t$ is the build-up time interval in days, $B_{\max }$ is the maximum build-up possible $\left(\mathrm{kg} \mathrm{m}^{-1}\right), K_{B}$ is the build-up rate constant $\left(\mathrm{kg} / \mathrm{mday}^{-\mathrm{NB}}\right)$, and $N_{B}$ is the build-up time exponent (dimensionless). The time exponent, $N_{B}$, should be $\leq 1$ so that a decreasing rate of build-up occurs as time increases. When $N_{B}$ is set equal to 1 , a linear build-up function is obtained. Wash-off is the process of dissolving the constituents from catchment surface during the period of runoff. In this work, an event mean concentration (EMC) wash-off function has been applied according to [35] and presented in Equation (4):

$$
w=K_{w} q f_{l u A}
$$

where, $K w$ is the EMC expressed in the same volumetric units as flow rate. $q f l u A$ is the fraction of the total runoff rate that applies to the land use. Most of the urbanized areas for this case study are covered by highly populated residential land use, followed by commercial, industry, park, and road zones. Total Suspended Solids (TSS) has been chosen as an indicator of the runoff quality. TSS is one of the basic indicators of urban runoff pollution as some of the nutrients and metals are transported attached to the particles. 


\subsection{Assessing Optimal GI Measures}

\subsubsection{Optimisation Procedure}

The optimisation procedure consists of adjusting the number of GI units, taking into account their location within the catchment area. For this purpose, the NSGA-II optimiser algorithm that was developed by [21] was used with the goal of finding a representative set of optimal Pareto solutions and to quantify the trade-offs between pollution load, peak runoff, flood volume, and investment cost. Figure 3 illustrates the proposed optimisation procedure. The optimisation steps include: (1) computation of the initial value of variables, in this case, the maximum number of GI units and its maximum costs, (2) the initial simulation of the hydraulic and quality model, (3) computation of the maximum values of pollution load, peak runoff, and flooding volume for different return periods of rainfall, (4) computation of the objective functions, (5) running the optimiser NSGA-II according to the number of populations and generations, and (6) updating the hydrodynamic input file by changing the number of equal size units of the GI (e.g., the number of bio-retention cells) deployed in each subcatchment if the number of populations and generations has not been reached.

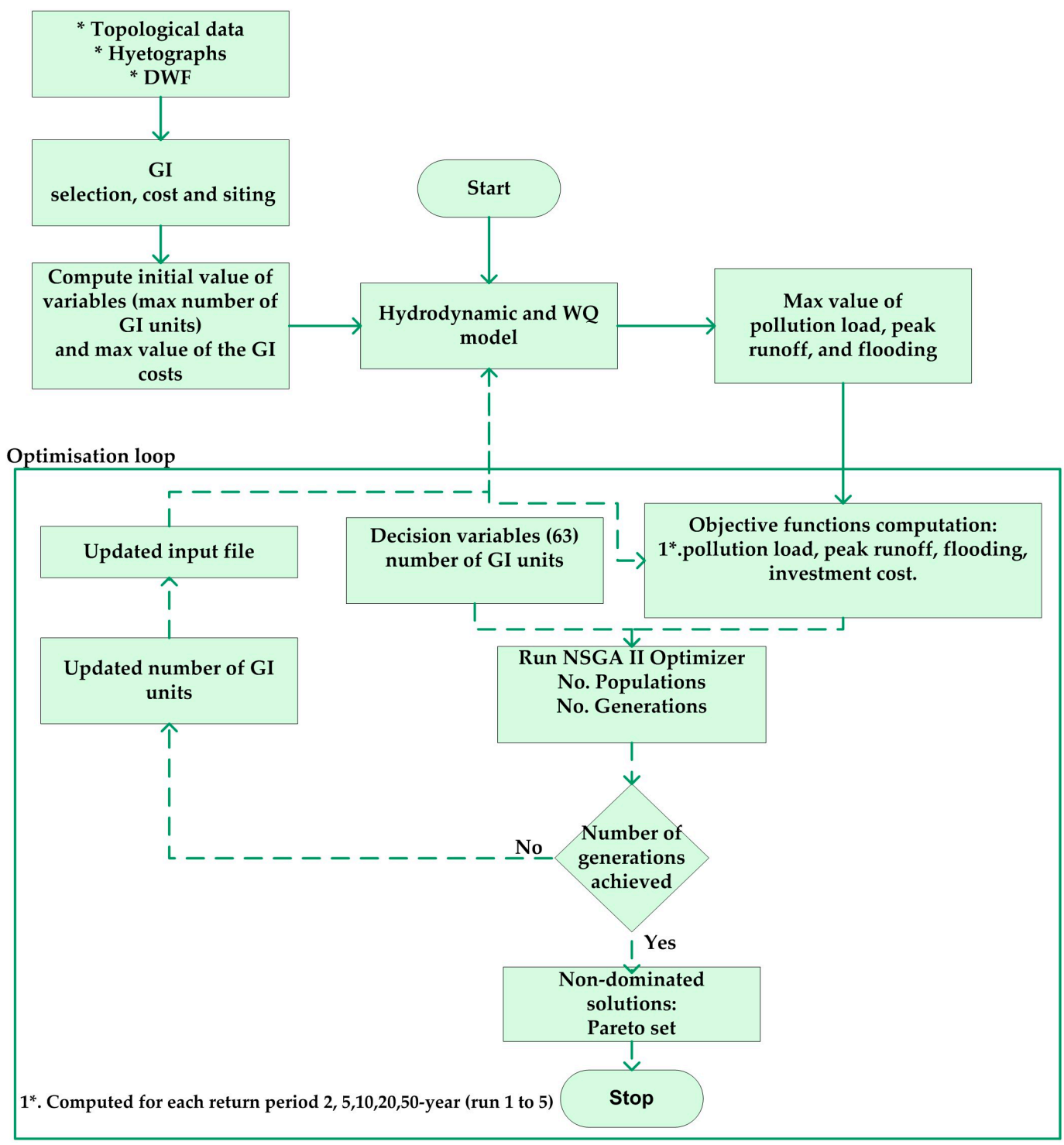

Figure 3. The optimisation procedure. 


\subsubsection{Linkage between the Hydrodynamic Model and NSGA-II Optimiser}

Two interfacing routines were developed and coded using LAZARUS, a free-source Delphi compatible cross-platform IDE for rapid application development to join the NSGA-II optimiser with the hydrodynamic model. The hydrodynamic input file specifies how a particular GI is deployed. The data entry fields include the GI type and its number of units (i.e., decision variables) for each subcatchment. The first routine was coded to run the hydrodynamic model, set the initial value of variables and compute the normalized values of the objective functions. The maximum value of GI investment cost is also computed from a catalogue file that contains the GI unit cost.

The NSGA-II optimiser generates a file with the lower and upper range values of the decision variables. The second routine was also coded to run the model and update the hydrodynamic input file. This routine uses the generated file with the decision variables range to modify the number of GI units by overwritten its value in the hydrodynamic input file for each iteration. With this procedure, a new objective function value is obtained. Optimisation parameters for the NSGA-II algorithm were set to a population size of 200 and 30 generations for a total number of function evaluations of 6000 . The probability of crossover was set to 0.90 , the probability of mutation to 0.09 , the distribution index for crossover to 15 , and the distribution index for mutation to 20 .

\subsubsection{Objective Functions}

In order to quantify the trade-offs between the reductions objectives, three objective functions were coded: pollution load, peak runoff, and flood volume with their corresponding reductions in investment costs. The objective functions are presented as follows:

Pollution Load Reduction

The maximum wash-off of TSS in the urban drainage system is used for the evaluation of percentage reduction of TSS. The objective function calculates the average of TSS wash-off for each subcatchment using Equation (5).

$$
f_{1}\left(x_{i}\right)=\frac{1}{n} \cdot \sum_{j=1}^{n} \frac{w f_{j}}{w f_{j, \max }}
$$

where, $f_{1}\left(x_{i}\right)$ is the fitness function 1 of chromosome $i, n$ is the number of subcatchments, $j$ is the subcatchment number, $w f_{j}$ is the TSS wash-off ( $\mathrm{kg} /$ day) of the subcatchment $j$, and $w f_{j, \max }$ is the maximum TSS wash-off load (kg/day) in the system without using any GI type in each subcatchment $j$.

\section{Peak Runoff Reduction}

In the model, surface runoff occurs when the depth of water exceeds the maximum depression storage so that the peak runoff value is taken from the model system response through its hydrograph [36]. The objective function consists of calculating the average of each normalized runoff peak of each subcatchment, as follows:

$$
f_{2}\left(x_{i}\right)=\frac{1}{n} \cdot \sum_{j=1}^{n} \frac{p r_{j}}{p r_{j, \max }}
$$

where, $f_{2}\left(x_{i}\right)$ is the fitness function 2 of chromosome $i, n$ is the number of subcatchments, $j$ is the subcatchment number, $p r_{j}$ is the peak runoff $\left(\mathrm{m}^{3} / \mathrm{s}\right)$ of subcatchment $j$, and $p r_{j, \max }$ is the maximum runoff in the system without using any GI type in each subcatchment $j$.

Flood Volume Reduction

In the model, flooding occurs when the water depth at a node exceeds the maximum available depth, and the excess flow is either lost from the system or can pond on top of the node and re-enter the drainage system [36]. This objective function focuses on evaluating the flooding volume reduction 
in terms of the maximum flooding volume obtained from the model simulations. It consists of the sum of the volume of all the nodes divided by the sum of flood volume coming from the system without using any GI type in each subcatchment $j$.

$$
f_{3}\left(x_{i}\right)=\frac{\sum_{j=1}^{n} n f v_{j}}{n f v_{j, \max }}
$$

where, $f_{3}\left(x_{i}\right)$ is the fitness function 3 of chromosome $\mathrm{i}, n$ is the number of flood conflicting nodes, $j$ is the node number, $n f v_{j}$ is the flood volume $\left(\mathrm{m}^{3}\right)$ of node $j$, and $n f v_{j, \text { max }}$ is the maximum flooding volume coming from the system without using any GI type in each subcatchment $j$.

\section{Investment Cost Function}

The investment cost of each GI configuration system is related to the total number of GI units that were implemented in each subcatchment multiplied by their implementation cost. The number of GIs results from the optimisation process, while the implementation cost is calculated from the catalogue that contains unit costs for different GIs. This is presented in the following Equation (8).

$$
f_{4}\left(x_{i}\right)=\frac{\sum_{j=1}^{n}\left(\mathrm{GI} \operatorname{cost}_{j} \cdot \mathrm{GI} \cdot \text { number }_{j}\right)}{\operatorname{cost}_{\max }}
$$

where, $f_{4}\left(x_{i}\right)$ is the fitness function 4 of solution $i$, GI.cost $t_{j}$ is the cost (US dollars $/ \mathrm{m}^{2}$ ) of GI type $j$, GI.number $r_{j}$ is the number of GI type $j$, and cost $_{\text {max }}$ is the maximum implementation cost.

The output of the optimisation procedure include non-dominated solutions with the number of GI units to be implemented for lowest possible cost and for return period events of 2, 5, 10, 20, and 50 years. The percentage of reduction reached has been computed taking into account the objective function value (O.F) obtained from the optimisation process and the maximum objective function value without using any GI type, as follows:

$$
100-\frac{[\text { O.F value }(\text { opt. solution }) * 100]}{\text { Max O.F value }(\text { present state })}
$$

\subsubsection{Maximum GI Investment Cost}

The maximum GI investment cost was calculated by adding the investment cost to the operation and maintenance cost per square meter of each GI type for 20 years. A unit cost was computed based on the cost categories according to the layers of the GI (i.e., surface, soil, storage, underdrain). An inflation rate of $2.8 \%$ was used in order to calculate the net present value of each unit [39] and the base prices were taken from the city price index [40]. The investment cost for all types of BR included less cost for the surface layer due to the lower costs of local grass. Investment costs for different types of IT might vary from one place to another due to the variation in local gravel costs. The overall project investment cost using this maximum number of GI units was found to be \$19.9 million dollars. This value was obtained according to the maximum number of units of each GI type and its corresponding unit cost (see the summary table of GI in Appendix A).

\section{Results and Discussion}

\subsection{Initial Performance of the Drainage System}

The hydrodynamic model was run for the selected return period events of 2, 5, 10, 20, and 50 years without implementing any of the GI measures (i.e., present state). Simulation results indicate a peak runoff of $147,171,185,200$, and $227 \mathrm{~m}^{3} / \mathrm{s}$, respectively. The TSS loading at the outfall of the system was found to be 37,$348 ; 40,388 ; 42,635 ; 45,184 ;$ and, $49,113 \mathrm{~kg} /$ day, respectively. 


\subsection{GI Placement}

Potential suitable location/areas for different types of GI were identified from the analysis of urban land use, stream location, soil classification, land ownership, and impervious layers. The placement of GIs was carried out by finding the available space for GI in each subcatchment. The minimum percentage of available area (ha) was found to be $2.8 \%$ and the maximum $32 \%$. Figure 4 presents the maximum number of GI units for each subcatchment. With the criteria presented in Section 3.2.2, the maximum number of GI units found was 468 divided, as follows: 116 units of BR, 116 units of IT, 164 units of vs. and 72 units of PP. Figure 5 depicts an example of the TSS loading in each subcatchment for a five-year return period event before and after GI placement (applying the maximum number of units). On average, a reduction of $40 \%$ of TSS could be potentially obtained after implementing GI measures.

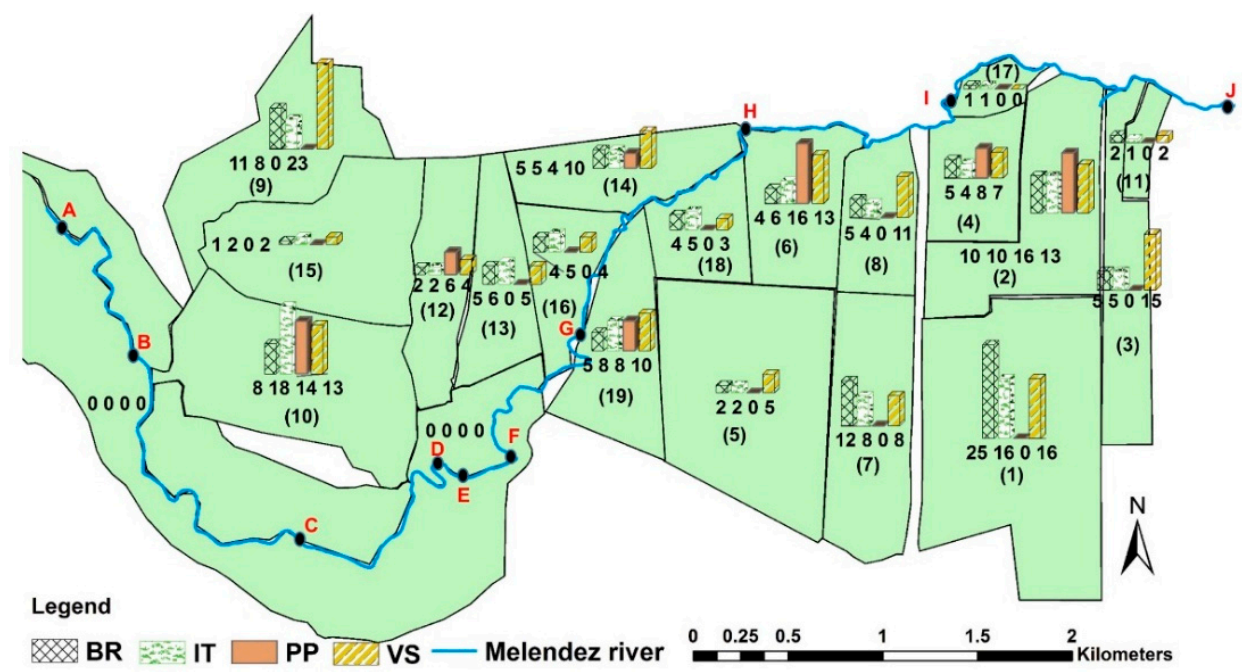

Figure 4. Maximum number of GI units in the Melendez catchment (subcatchment numbers in brackets).

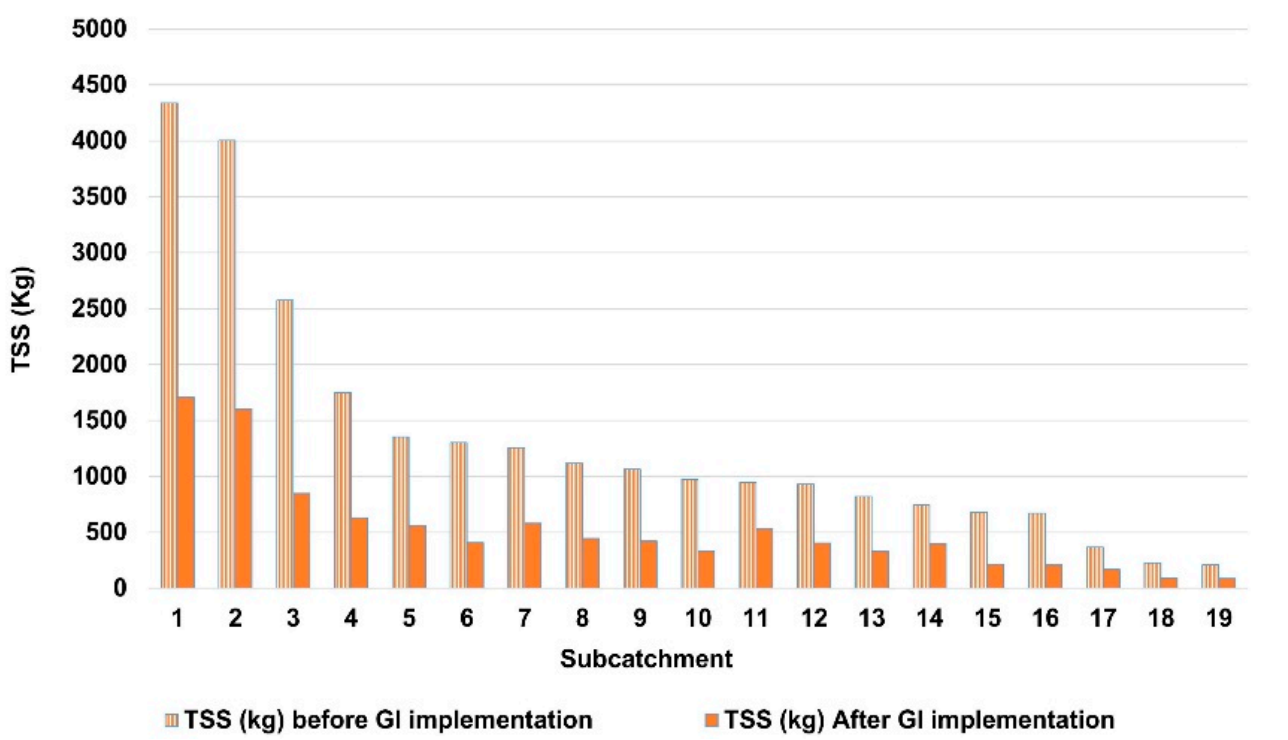

Figure 5. TSS (kg/day) for each subcatchment.

The second hydrodynamic model run was carried out for 2, 5, 10, 20, and 50-year return period events with the maximum number of GI units (i.e., 468 units). Simulation results indicate a peak runoff reduction to $114,131,140,153$, and $172 \mathrm{~m}^{3} / \mathrm{s}$, respectively. Also, the reduction of TSS at the outfall of the system was found to be 22,$737 ; 24,955 ; 26,717 ; 28,585 ;$ and, $31,471 \mathrm{~kg}$ /day, respectively. 


\subsection{Assessing Optimal GI Measures}

In order to obtain optimal GI solutions distributed within the catchment, a trade-off between each objective reduction (i.e., pollution load, peak runoff, flooding volume) and investment costs was introduced as an optimisation problem. As described above, four different GI measures were evaluated (BR, IT, vs. and PP) and the selection of these measures were described in Section 3.2. These measures were evaluated by running simulations for 2, 5, 10, 20, and 50-year return period events. The maximum number of GI units was a subject of the optimisation process. Figure 6 shows the non-dominated solutions obtained for the mentioned objectives.

(a)

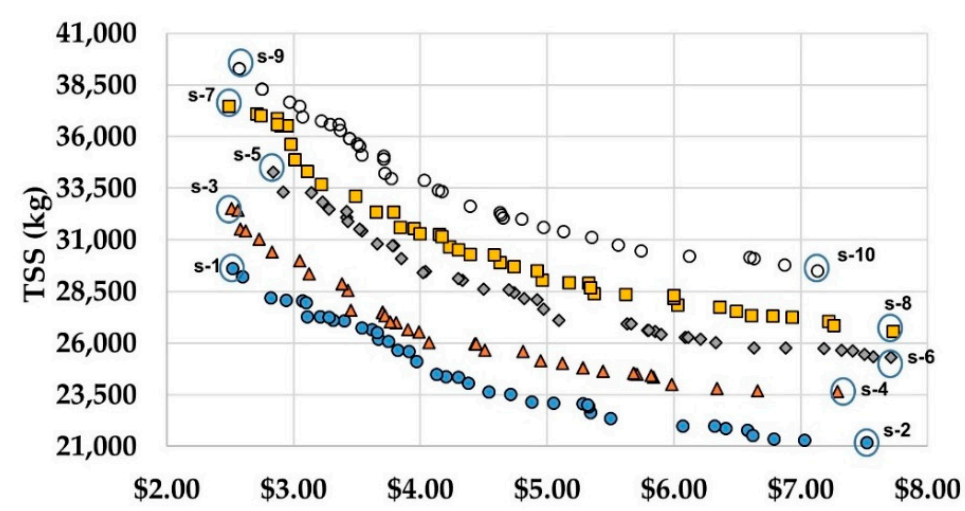

(b)

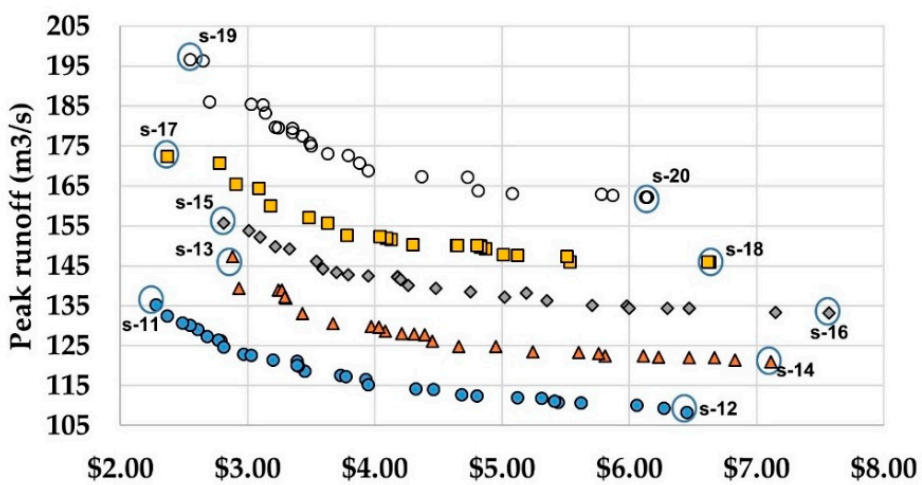

(c)

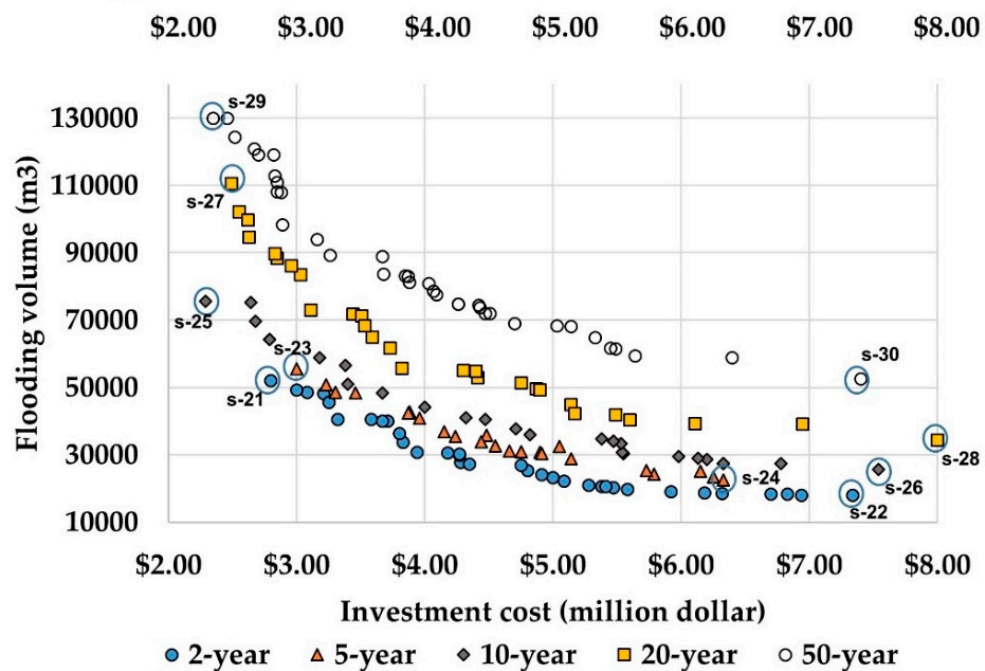

Figure 6. The non-dominated solutions obtained for different objectives (a) pollution load; (b) peak runoff; and, (c) flood volume. Two solutions were initially selected from each return period; the first solution corresponds to a very low objective reduction and minimum investment cost. The second solution corresponds to a very high investment cost and maximum objective reduction. 
Figure 6a shows that for smaller events, with solution s-2 an investment of $\$ 7.5$ million can achieve a pollution load reduction of $43 \%$. For larger return period events (up to 50 years) a $\$ 7$ million investment suggests a pollution load reduction of $40 \%$ (solution s-10). In terms of peak runoff reduction, Figure $6 \mathrm{~b}$ presents solution s- 12 with a peak runoff reduction of $30 \%$ by investing $\$ 6.4$ million for a two-year event. With solution s-20 it is possible to reduce peak runoff by $27 \%$ for a 50 -year event and $\$ 6$ million investment. Figure 6c presents optimal solutions for flood volume reduction. Solution s-22 shows a reduction level of $80 \%$ for a two-year event with an investment cost of $\$ 7.3$ million. Solution s-30 demonstrates a flooding volume reduction of $68 \%$ by investing $\$ 7.4$ million (up to 50 years).

Table 2 presents the comparison of the selected solutions for each objective reduction. The catchment points (letters in red colour) that are presented in Figure 4 have been used for comparison purposes between the present state (no GI placement) and the computed optimal solutions.

Table 2. Comparison of the selected solutions.

\begin{tabular}{|c|c|c|c|c|c|c|c|c|c|c|}
\hline \multirow[b]{2}{*}{$\begin{array}{l}\text { Catchment } \\
\text { Point }\end{array}$} & \multirow[b]{2}{*}{$\begin{array}{l}\text { Return } \\
\text { Period }\end{array}$} & \multicolumn{3}{|c|}{ TSS (kg) } & \multicolumn{3}{|c|}{ Peak Runoff $\left(\mathrm{m}^{3} / \mathrm{s}\right)$} & \multicolumn{3}{|c|}{ Flooding Volume $\left(\mathrm{m}^{3}\right)$} \\
\hline & & $\begin{array}{c}\text { Present } \\
\text { State } \\
\text { (no GI) }\end{array}$ & $\begin{array}{c}\text { Optimal } \\
\text { Solution } \\
\text { s-2 }\end{array}$ & $\begin{array}{c}\text { Optimal } \\
\text { Solution } \\
\text { s-10 }\end{array}$ & $\begin{array}{l}\text { Present } \\
\text { State } \\
\text { (no GI) }\end{array}$ & $\begin{array}{c}\text { Optimal } \\
\text { Solution } \\
\text { s-12 }\end{array}$ & $\begin{array}{c}\text { Optimal } \\
\text { Solution } \\
\text { s-20 }\end{array}$ & $\begin{array}{c}\text { Present } \\
\text { State } \\
\text { (no GI) }\end{array}$ & $\begin{array}{c}\text { Optimal } \\
\text { Solution } \\
\text { s-22 }\end{array}$ & $\begin{array}{c}\text { Optimal } \\
\text { Solution } \\
\text { s-30 }\end{array}$ \\
\hline \multirow{2}{*}{ G } & 2 & 2433 & 924 & - & 3.72 & 1.88 & - & 5654 & 933 & - \\
\hline & 50 & 2976 & - & 1,286 & 4.59 & - & 1.71 & 8111 & - & 2470 \\
\hline \multirow{2}{*}{$\mathrm{H}$} & 2 & 659 & 276 & - & 5.02 & 2.96 & - & 6279 & 1364 & - \\
\hline & 50 & 799 & - & 281 & 6.28 & - & 3.71 & 37,802 & - & 9914 \\
\hline \multirow{2}{*}{ I } & 2 & 195 & 83 & - & 0.94 & 0.55 & - & 27,964 & 12,455 & \\
\hline & 50 & 244 & - & 114 & 1.18 & - & 0.75 & 34,177 & - & 21,656 \\
\hline \multirow[b]{2}{*}{$\mathrm{J}$} & 2 & 215 & 89 & - & 1.47 & 0.79 & - & - & - & - \\
\hline & 50 & 262 & - & 110 & 1.83 & - & 1.34 & - & - & - \\
\hline
\end{tabular}

Solutions s-2 and s-10 indicate an important pollution decrease, especially where the water quality deterioration in points G, H, I, and J of the Meléndez catchment is very significant. Solution s-12 and solution s-20 are able to regulate the flow of the river when a rainfall event occurs in the upper part of the catchment (points $\mathrm{A}, \mathrm{B}$, and $\mathrm{C}$ ), and thus reduce the river flow at the entrance of the city (between points $\mathrm{G}$ and $\mathrm{H}$ ). Solution s-22 and solution s-30 indicate the possibility of reducing the risk of flooding, particularly in points $\mathrm{H}$ and I where the highest flood volumes occur in a mostly residential area. Figure 6 presents the optimal number of units with the aim of identifying the GI type that better reduce the three objectives for the study area.

As it can be seen from Figure 7, GI types, such as infiltration trench (IT02) and vegetative swale (VS01) for small and large events present the largest number of GI units deployed in the catchment reducing the three objectives. Comparing these numbers with the results that were obtained in Figure 6 and Table 2, a larger number of IT02 and VS01 would have an effect on improving runoff quality and quantity when compared to bio-retention cells (BR) and porous pavement (PP), despite the small differences in the investment costs. According to the characteristics of the GI design shown in Table 1, IT02 could have been more placed due to the rate value at which water seeps into the native soil below the layer (greater than IT01).

Through the analysis of these results, it can be observed that BR02 has been mainly used with the purpose of reducing pollution load (solutions s-1 to s-10) as compared to the other two objectives. From the three types of BR, BR02 differs from the other two due to the thickness of the soil layer, the rate value at which water seeps into the native soil below the layer (both greater than BR01 and BR03) and the draining type (it uses infiltration rather than underdrains). In line with the design characteristics, for larger events the use of PP01 in the catchment increases in solutions s- 8 and s-10 for pollution load reduction and solutions s-18 and s-30 for peak runoff and flooding volume reduction, respectively. 

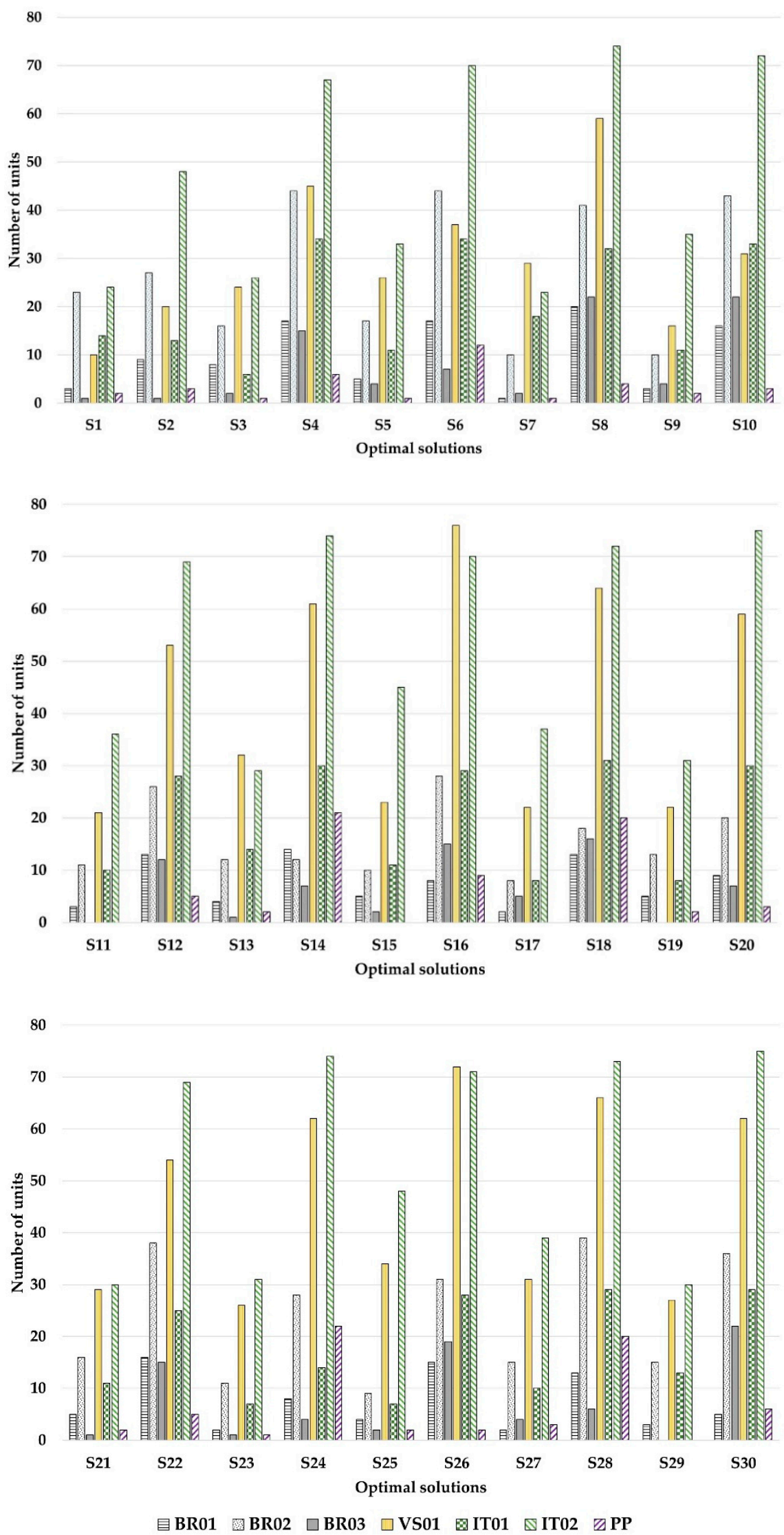

Figure 7. Optimal number of GI units associated with solutions. 
The main constraint of these optimal solutions is the amount of financial resources that is required to the initial GI implementation, which is $\$ 19.9$ million dollars. Within this framework important investment cost reductions were obtained in terms of pollution load, peak runoff, and flooding volume to $\$ 7$ million, $\$ 6$ million, and $\$ 7.4$ million, respectively, for events up to 50 years. In terms of the effect of a rapid increase in rainfall intensity and similar to the work that is presented in [41], different return periods $(2,5,10,20$, and 50-year) enable not only a better understanding to achieve optimal solutions but also an effective GI placement minimizing erroneous and costly intervention for urban runoff reduction.

According to other researches, although we manually determined subcatchment parameters and GI process layers, much of this work could be automated. However, it is important to consider the stakeholders input into the final design decisions for each subcatchment, possibly iteratively applying this framework with additional constrains until a satisfactory solution is found see [22,25,27]. The methodological framework that is presented here demonstrates a possible way to select one solution from different alternatives. For the case study area of Cali, these solutions that can maximise environmental and economic objectives for up to a 50-year return period event could be considered as preferred. However, since different GI type units can produce a similar performance, the preferred combination of GIs would depend on the objectives that need to be achieved. In our future work, we will address such issues by incorporating a preference-based multi-objective model within the present methodological framework.

\section{Conclusions}

The present paper describes a novel methodological framework that aims to configure GI for urban runoff and pollutant reduction using the optimal number of units. The present work addressed the assessment of the performance of GI measures dealing with environmental and economic objectives. The proposed methodological framework has been implemented in the coding environment LAZARUS, which is a free-source Delphi compatible cross-platform. The code combines a hydrodynamic model and an optimisation algorithm. Simulations of hydraulic, hydrologic and quality aspects were performed within the SWMM package, while the NSGA-II model was used for process optimisation. The mass of a pollutant transported during a storm event has been modelled as a coupled build-up and wash-off process, providing the stormwater pollutant load that is generated from the urban catchment. The work was demonstrated in a real-life case study of Cali (Colombia) where bio-retention-cells (BR), infiltration trenches (IT), vegetative swales (VS), and porous pavement (PP) were evaluated while considering pollution load, peak runoff, and flood volume objectives at the lowest possible investment cost.

There are currently actions that are aiming to reduce the pollution load in the Meléndez river, but its water quality is still continuing to decline. Similarly, in spite of substantial investment in flood control structures in the catchment, there is still the risk of flooding as the investments are not executed according to their priority and their true impact in the catchment.

The results of this study show that by investing an amount of $\$ 7.7$ million with a higher number of BR units (up to 83 units) within a specific configuration, a pollution load reduction for larger events can be obtained with solution s-10. The solutions also show that an increase in the number of vs. units (up to 76 units) with the same investment can yield a reduction in peak runoff for both smaller and larger events (s-16 and s-18). Similarly, with the same level of investment and with a larger number of PP units (up to 22 units), solution s-30 would help to reduce flood volume for shorter and larger events.

The application of multi-objective optimisation processes for GI configuration may become a good choice in terms of reducing investment cost without compromising the efficiency of the drainage system. The results show an advantage of having an optimal number of GIs, as the GI types mainly reflect the impact on the reduction of the three objectives. This suggests that if the type of GI measure and its number of units are taken into account within the optimisation process, it is possible to achieve optimal solutions to reduce the proposed reduction objectives with a lower investment cost. 
In terms of disadvantages, one of the key disadvantages is that this approach is not able to incorporate surface water infiltration process into the hydrodynamic model based on a given infiltration equation (i.e., modified Horton method) in a 1D-2D modelling approach while taking into account the expensive computational time which limits its application for real-life purposes.

The present work also demonstrates how different performance can be used to address different objectives and to identify a solution that can be suitable for the study area. In our future research, we plan to extend the present methodological framework by taking into consideration a preference-based multi-objective model that can reflect different preferences for different performance measures.

Author Contributions: C.M. and A.S. contributed in terms of the framework development, building the interfacing model routines, GI implementation, model simulations and article writing. R.G. contributed to the selection and cost of GI and building the interfacing model routines. A.M. participated in the process of setting up the water quality model. The research process was performed under the close supervision of, and received contributions from, A.S., Z.V., and A.G.

Funding: This work was supported by the Administrative Department of Science, Technology and Innovation, COLCIENCIAS under Grant No. 568 of 2012 and the Advanced Training Program for Teaching and Research of the Universidad del Magdalena, Colombia awarded to the first author. The research leading to these results has also received partial funding from the European Union Seventh Framework Programme under Grant Agreement No. 603663 for the research project PEARL.

Conflicts of Interest: The authors declare no conflict of interest. 


\section{Appendix A}

Table A1. Summary table of the implemented GI.

\begin{tabular}{|c|c|c|c|c|c|c|c|c|c|c|c|c|c|}
\hline Sub Catchment & GI Type & $\begin{array}{l}\text { Area } \\
\text { (Ha) }\end{array}$ & $\%$ Imper & $\begin{array}{l}\text { Drainage } \\
\text { Area (Ha) }\end{array}$ & $\begin{array}{c}\text { Flow } \\
\left(\mathrm{m}^{3} / \mathrm{s}\right)\end{array}$ & $\begin{array}{c}\text { Volume } \\
\left(\mathrm{m}^{3}\right)\end{array}$ & $\begin{array}{l}\text { Size Depth } \\
\text { (m) }\end{array}$ & $\begin{array}{l}\text { Width } \\
\text { (m) }\end{array}$ & $\begin{array}{c}\text { Unit Area } \\
\left(\mathrm{m}^{2}\right)\end{array}$ & GI \# Units & $\begin{array}{c}\text { \% Imper } \\
\text { Area Treated }\end{array}$ & GI Unit Cost & GI Total Cost \\
\hline \multirow[t]{4}{*}{1} & & 126.58 & 0.72 & & & & & & & & & & \\
\hline & BR03 & & & 2 & 202 & 4858 & 1.6 & & 3036 & 25 & 54.76 & $\$ 27,439$ & $\$ 685,726$ \\
\hline & IT02 & & & 2 & 202 & 4858 & 1.4 & 7.5 & 3470 & 16 & 35.05 & $\$ 30,812$ & $\$ 308,119$ \\
\hline & VS01 & & & & 51 & 1214 & 1.6 & 10 & 759 & 16 & 8.76 & $\$ 23,966$ & $\$ 383,448$ \\
\hline \multirow[t]{5}{*}{2} & & 65.08 & 0.76 & & & & & & & & & & \\
\hline & BR02 & & & 2 & 212 & 5099 & 1.6 & & 3187 & 10 & 40.59 & $\$ 32,122$ & $\$ 321,224$ \\
\hline & IT02 & & & 2 & 212 & 5099 & 1.4 & 7.5 & 3642 & 10 & 40.59 & $\$ 30,812$ & $\$ 308,119$ \\
\hline & VS01 & & & 0.5 & 53 & 1275 & 1.6 & 10 & 797 & 13 & 13.19 & $\$ 23,966$ & $\$ 311,552$ \\
\hline & PP01 & & & 0.054 & & & & 6 & 540 & 16 & 1.75 & $\$ 122,812$ & $\$ 1,964,990$ \\
\hline \multirow[t]{4}{*}{3} & & 39.58 & 0.72 & & & & & & & & & & \\
\hline & BR02 & & & 2 & 202 & 4849 & 1.6 & & 3030 & 5 & 35.09 & $\$ 32,122$ & $\$ 160,612$ \\
\hline & IT02 & & & 2 & 202 & 4849 & 1.4 & 7.5 & 3463 & 5 & 35.09 & $\$ 30,812$ & $\$ 154,059$ \\
\hline & VS01 & & & 0.5 & 51 & 1212 & 1.6 & 10 & 758 & 15 & 26.32 & $\$ 23,966$ & $\$ 359,483$ \\
\hline \multirow[t]{5}{*}{4} & & 29.03 & 0.76 & & & & & & & & & & \\
\hline & BR02 & & & 2 & 212 & 5095 & 1.6 & & 3185 & 5 & 45.53 & $\$ 32,122$ & $\$ 160,612$ \\
\hline & IT01 & & & 2 & 212 & 5095 & 1.4 & 7.5 & 3639 & 4 & 36.42 & $\$ 30,182$ & $\$ 123,248$ \\
\hline & VS01 & & & 0.5 & 53 & 1274 & 1.6 & 10 & 796 & 7 & 15.94 & $\$ 23,966$ & $\$ 167,759$ \\
\hline & PP01 & & & 0.054 & & & & 6 & 540 & 8 & 1.97 & $\$ 122,182$ & $\$ 982,495$ \\
\hline \multirow[t]{4}{*}{5} & & 97.57 & 0.11 & & & & & & & & & & \\
\hline & BR03 & & & 2 & 31 & 736 & 1.6 & & 460 & 2 & 37.51 & $\$ 27,429$ & $\$ 54,858$ \\
\hline & IT01 & & & 2 & 31 & 736 & 1.4 & 7.5 & 526 & 2 & 37.51 & $\$ 30,812$ & $\$ 61,624$ \\
\hline & VS01 & & & 0.5 & 8 & 184 & 1.6 & 10 & 115 & 5 & 23.44 & $\$ 23,966$ & $\$ 119,828$ \\
\hline \multirow[t]{5}{*}{6} & & 41.5 & 0.67 & & & & & & & & & & \\
\hline & BR02 & & & 2 & 188 & 4508 & 1.6 & & 2818 & 4 & 28.80 & $\$ 32,122$ & $\$ 128,490$ \\
\hline & IT02 & & & 2 & 188 & 4508 & 1.4 & 7.5 & 3220 & 6 & 43.20 & $\$ 30,812$ & $\$ 184,871$ \\
\hline & VS01 & & & 0.5 & 47 & 1127 & 1.6 & 10 & 704 & 13 & 23.40 & $\$ 23,966$ & $\$ 311,552$ \\
\hline & PP01 & & & 0.054 & & & & 6 & 540 & 16 & 3.11 & $\$ 122,812$ & $\$ 1,964,990$ \\
\hline \multirow[t]{4}{*}{7} & & 58.65 & 0.76 & & & & & & & & & & \\
\hline & BR02 & & & 2 & 214 & 5125 & 1.6 & & 3203 & 12 & 53.77 & $\$ 32,122$ & $\$ 385,469$ \\
\hline & IT02 & & & 2 & 214 & 5125 & 1.4 & 7.5 & 3661 & 8 & 35.85 & $\$ 29,508$ & $\$ 246,495$ \\
\hline & VS01 & & & 0.5 & 53 & 1281 & 1.6 & 10 & 801 & 8 & 8.96 & $\$ 23,965$ & $\$ 191,724$ \\
\hline \multirow[t]{4}{*}{8} & & 31.57 & 0.76 & & & & & & & & & & \\
\hline & BR02 & & & 2 & 212 & 5090 & 1.6 & & 3181 & 5 & 41.91 & $\$ 32,122$ & $\$ 160,612$ \\
\hline & IT02 & & & 2 & 212 & 5090 & 1.4 & 7.5 & 3636 & 4 & 33.53 & $\$ 30,812$ & $\$ 118,033$ \\
\hline & VS01 & & & 0.5 & 53 & 1272 & 1.6 & 10 & 795 & 11 & 23.05 & $\$ 23,966$ & $\$ 263,615$ \\
\hline
\end{tabular}


Table A1. Cont.

\begin{tabular}{|c|c|c|c|c|c|c|c|c|c|c|c|c|c|}
\hline Sub Catchment & GI Type & $\begin{array}{l}\text { Area } \\
\text { (Ha) }\end{array}$ & \% Imper & $\begin{array}{l}\text { Drainage } \\
\text { Area (Ha) }\end{array}$ & $\begin{array}{c}\text { Flow } \\
\left(\mathrm{m}^{3} / \mathrm{s}\right)\end{array}$ & $\begin{array}{c}\text { Volume } \\
\left(\mathrm{m}^{3}\right)\end{array}$ & $\begin{array}{l}\text { Size Depth } \\
\text { (m) }\end{array}$ & $\begin{array}{l}\text { Width } \\
\text { (m) }\end{array}$ & $\begin{array}{c}\text { Unit Area } \\
\left(\mathrm{m}^{2}\right)\end{array}$ & GI \# Units & $\begin{array}{c}\text { \% Imper } \\
\text { Area Treated }\end{array}$ & GI Unit Cost & GI Total Cos \\
\hline \multirow[t]{4}{*}{9} & & 61.32 & 0.81 & & & & & & & & & & \\
\hline & BR01 & & & 2 & 228 & 5474 & 1.6 & & 3421 & 11 & 44.14 & $\$ 32,122$ & $\$ 353,347$ \\
\hline & IT01 & & & 2 & 228 & 5474 & 1.4 & 7.5 & 3910 & 8 & 32.10 & $\$ 30,812$ & $\$ 246,495$ \\
\hline & VS01 & & & 0.5 & 57 & 1369 & 1.6 & 10 & 855 & 23 & 23.07 & $\$ 23,966$ & $\$ 551,207$ \\
\hline \multirow[t]{5}{*}{10} & & 87.57 & 0.80 & & & & & & & & & & \\
\hline & BR01 & & & 2 & 224 & 5388 & 1.6 & & 3367 & 8 & 22.84 & $\$ 31,122$ & $\$ 256,979$ \\
\hline & IT01 & & & 2 & 224 & 5388 & 1.4 & 7.5 & 3848 & 18 & 51.39 & $\$ 30,811$ & $\$ 554,602$ \\
\hline & VS01 & & & 0.5 & 56 & 1347 & 1.6 & 10 & 842 & 13 & 9.28 & $\$ 23,966$ & $\$ 311,552$ \\
\hline & PP01 & & & 0.054 & & & & 6 & 540 & 14 & 1.08 & $\$ 122,812$ & $\$ 1,719,366$ \\
\hline \multirow[t]{4}{*}{11} & & 68.76 & 0.10 & & & & & & & & & & \\
\hline & BR01 & & & 2 & 29 & 694 & 1.6 & & 434 & 1 & 28.21 & $\$ 32,122$ & $\$ 32,122$ \\
\hline & IT01 & & & 2 & 29 & 694 & 1.4 & 7.5 & 496 & 2 & 56.42 & $\$ 30,812$ & $\$ 61,624$ \\
\hline & VS01 & & & 0.5 & 7 & 174 & 1.6 & 10 & 108 & 2 & 14.11 & $\$ 23,966$ & $\$ 47,931$ \\
\hline \multirow{5}{*}{12} & & 34.91 & 0.30 & & & & & & & & & & \\
\hline & BR02 & & & 2 & 84 & 2020 & 1.6 & & 1263 & 2 & 38.19 & $\$ 32,122$ & $\$ 64,245$ \\
\hline & IT02 & & & 2 & 84 & 2020 & 1.4 & 7.5 & 1443 & 2 & 38.19 & $\$ 30,812$ & $\$ 61,624$ \\
\hline & VS01 & & & 0.5 & 21 & 505 & 1.6 & 10 & 316 & 4 & 19.10 & $\$ 23,966$ & $\$ 95,862$ \\
\hline & PP01 & & & 0.054 & & & & 6 & 540 & 6 & 3.09 & $\$ 122,812$ & $\$ 736,871$ \\
\hline \multirow[t]{4}{*}{13} & & 32.45 & 0.77 & & & & & & & & & & \\
\hline & BR02 & & & 2 & 215 & 5159 & 1.6 & & 3225 & 5 & 40.23 & $\$ 32,122$ & $\$ 160,612$ \\
\hline & IT02 & & & 2 & 215 & 5159 & 1.4 & 7.5 & 3685 & 6 & 48.27 & $\$ 30,812$ & $\$ 184,871$ \\
\hline & VS01 & & & 0.5 & 54 & 1290 & 1.6 & 10 & 806 & 5 & 10.06 & $\$ 23,966$ & $\$ 119,828$ \\
\hline \multirow[t]{5}{*}{14} & & 37.56 & 0.67 & & & & & & & & & & \\
\hline & BR02 & & & 2 & 189 & 4526 & 1.6 & & 2828 & 5 & 39.62 & $\$ 32,122$ & $\$ 160,612$ \\
\hline & IT02 & & & 2 & 189 & 4526 & 1.4 & 7.5 & 3233 & 5 & 39.62 & $\$ 30,812$ & $\$ 154,059$ \\
\hline & VS01 & & & 0.5 & 47 & 1131 & 1.6 & 10 & 707 & 10 & 19.81 & $\$ 23,966$ & $\$ 239,655$ \\
\hline & PP01 & & & 0.054 & & & & 6 & 540 & 4 & 0.86 & $\$ 122,812$ & $\$ 491,248$ \\
\hline \multirow[t]{4}{*}{15} & & 8.5 & 0.82 & & & & & & & & & & \\
\hline & BR01 & & & 2 & 231 & 5546 & 1.6 & & 3466 & 2 & 57.14 & $\$ 32,122$ & $\$ 64,245$ \\
\hline & IT01 & & & 2 & 231 & 5546 & 1.4 & 7.5 & 3961 & 1 & 28.57 & $\$ 30,812$ & $\$ 30,812$ \\
\hline & VS01 & & & 0.5 & 58 & 1386 & 1.6 & 10 & 867 & 2 & 14.29 & $\$ 23,966$ & $\$ 47,931$ \\
\hline \multirow[t]{4}{*}{16} & & 27.2 & 0.75 & & & & & & & & & & \\
\hline & BR02 & & & 2 & 210 & 5039 & 1.6 & & 3150 & 4 & 39.30 & $\$ 32,122$ & $\$ 128,490$ \\
\hline & IT02 & & & 2 & 210 & 5039 & 1.4 & 7.5 & 3600 & 5 & 49.13 & $\$ 30,812$ & $\$ 30,812$ \\
\hline & VS01 & & & 0.5 & 52 & 1260 & 1.6 & 10 & 787 & 4 & 9.83 & $\$ 23,966$ & $\$ 47,931$ \\
\hline \multirow[t]{3}{*}{17} & & 9.32 & 0.48 & & & & & & & & & & \\
\hline & BR02 & & & 2 & 135 & 3237 & 1.6 & & 2023 & 1 & 44.64 & $\$ 32,122$ & $\$ 32,122$ \\
\hline & IT02 & & & 2 & 135 & 3237 & 1.4 & 7.5 & 2312 & 1 & 44.64 & $\$ 30,812$ & $\$ 30,812$ \\
\hline
\end{tabular}


Table A1. Cont.

\begin{tabular}{|c|c|c|c|c|c|c|c|c|c|c|c|c|c|}
\hline Sub Catchment & GI Type & $\begin{array}{l}\text { Area } \\
\text { (Ha) }\end{array}$ & \% Imper & $\begin{array}{l}\text { Drainage } \\
\text { Area (Ha) }\end{array}$ & $\begin{array}{l}\text { Flow } \\
\left(\mathrm{m}^{3} / \mathrm{s}\right)\end{array}$ & $\begin{array}{c}\text { Volume } \\
\left(\mathrm{m}^{3}\right)\end{array}$ & $\begin{array}{l}\text { Size Depth } \\
\text { (m) }\end{array}$ & $\begin{array}{c}\text { Width } \\
\text { (m) }\end{array}$ & $\begin{array}{c}\text { Unit Area } \\
\left(\mathrm{m}^{2}\right)\end{array}$ & GI \# Units & $\begin{array}{c}\text { \% Imper } \\
\text { Area Treated }\end{array}$ & GI Unit Cost & GI Total Cos \\
\hline \multirow[t]{4}{*}{18} & & 25.7 & 0.77 & & & & & & & & & & \\
\hline & BR02 & & & 2 & 217 & 5217 & 1.6 & & 3261 & 4 & 40.18 & $\$ 32,122$ & $\$ 128,490$ \\
\hline & IT02 & & & 2 & 217 & 5217 & 1.4 & 7.5 & 3727 & 5 & 50.23 & $\$ 30,812$ & $\$ 154,059$ \\
\hline & VS01 & & & 0.5 & 54 & 1304 & 1.6 & 10 & 815 & 3 & 7.53 & $\$ 23,966$ & $\$ 71,897$ \\
\hline \multirow[t]{5}{*}{19} & & 40.72 & 0.78 & & & & & & & & & & \\
\hline & BR02 & & & 2 & 218 & 5225 & 1.6 & & 3265 & 5 & 31.66 & $\$ 32,122$ & $\$ 160,612$ \\
\hline & IT02 & & & 2 & 218 & 5225 & 1.4 & 7.5 & 3732 & 8 & 50.65 & $\$ 30,812$ & $\$ 246,495$ \\
\hline & VS01 & & & 0.5 & 54 & 1306 & 1.6 & 10 & 816 & 10 & 15.83 & $\$ 23,966$ & $\$ 239,655$ \\
\hline & PP01 & & & 0.054 & & & & 6 & 540 & 8 & 1.37 & $\$ 122,812$ & $\$ 982,495$ \\
\hline
\end{tabular}




\section{References}

1. Hilly, G.; Vojinovic, Z.; Weesakul, S.; Sanchez, A.; Hoang, D.; Djordjevic, S.; Chen, A.; Evans, B. Methodological Framework for Analysing Cascading Effects from Flood Events: The Case of Sukhumvit Area, Bangkok, Thailand. Water 2018, 10, 81. [CrossRef]

2. Ashley, R.; Balmforth, D.; Saul, A.; Blanskby, J. Flooding in the future-Predicting climate change, risks and responses in urban areas. Water Sci. Technol. 2005, 52, 265-273. [CrossRef] [PubMed]

3. Mailhot, A.; Duchesne, S. Design criteria of urban drainage infrastructures under climate change. Water Resour. Plan. Manag. 2010, 136, 201-208. [CrossRef]

4. Department of Environmental Conservation, New York State, Urban Stormwater Runoff. Available online: http: / / www.dec.ny.gov / chemical/69422.html\#Problem (accessed on 14 March 2018).

5. Novotny, B. Water Quality: Diffuse Pollution and Watershed Management, 2nd ed.; John Wiley and Sons: Hoboken, NJ, USA, 2003; ISBN 0-471-39633-8.

6. U.S. Environmental Protection Agency. National Nonpoint Source Program a Catalyst for Water Quality Improvements; EPA Publishing: Washington, DC, USA, 2016.

7. Yang, B.; Li, S. Green infrastructure design for stormwater runoff and water quality: Empirical evidence from large watershed-scale community developments. Water 2013, 5, 4. [CrossRef]

8. Ozgun, K.; Moulis, A.; Leardini, P. Water-potential-mapping for urban flood/drought resilience: A holistic approach to sustainable spatial planning and design by augmenting use, reuse and storage capacity of storm water in south east Queensland. In Proceedings of the International Conference on Changing Cities III: Spatial, Design, Landscape \& Socio-Economic dimensions, Syros-Delos-Mykonos Islands, Greece, 26-30 June 2017; University of Thessaly Volos: Volos, Greece.

9. Stovin, V.R.; Dunnett, N.; Hallam, A. Green Roofs-Getting Sustainable Drainage off the Ground. In Proceedings of the 6th International Conference of Sustainable Techniques and Strategies in Urban Water Management, Lyon, France, 25-28 June 2007; pp. 11-18.

10. Jayasooriya, $\mathrm{V}$; $\mathrm{Ng}$, A. Tools for modelling of stormwater management and economics of green infrastructure practices: A review. Water Air Soil Pollut. 2014, 225, 1-20. [CrossRef]

11. Shackleton, C.; Blair, A.; De Lacy, P.; Kaoma, H.; Mugwagwa, N.; Dalu, M.; Walton, W. How important is green infrastructure in small and medium-sized towns? Lessons from South Africa. Landsc. Urban Plan. 2016. [CrossRef]

12. Leroy, M.; Portet-Koltalo, F.; Legras, M.; Lederf, F.; Moncond'huy, V.; Polaert, I.; Marcotte, S. Performance of vegetated swales for improving road runoff quality in a moderate traffic urban area. Sci. Total Environ. 2016, 566-567, 113-121. [CrossRef] [PubMed]

13. Massoudieh, A.; Maghrebi, M.; Kamrani, B.; Nietch, C.; Treey, M.; Aflaki, S.; Panguluri, S. A flexible modelling framework for hydraulic and water quality performance assessment of stormwater green infrastructure. Environ. Model. Softw. 2017, 92, 57-73. [CrossRef]

14. Vojinovic, Z.; Keerakamolchai, W.; Weesakul, S.; Pudar, R.; Medina, N.; Alves, A. Combining ecosystem services with cost-benefit analysis for selection of green and grey infrastructure for flood protection in a cultural setting. Environments 2017, 4, 3. [CrossRef]

15. Alves, A.; Patiño, J.; Vojinovic, Z.; Sanchez, A.; Weesakul, S. Combining co-benefits and stakeholders perceptions into green infrastructure selection for flood risk reduction. Environments 2018, 5, 29. [CrossRef]

16. Vojinovic, Z.; Seyoum, S.; Salum, M.; Price, R.; Fikri, A.; Abebe, Y. Modelling floods in urban areas and representation of buildings with a method based on adjusted conveyance and storage characteristics. J. Hydroinform. 2012, 15, 1150-1168. [CrossRef]

17. Vojinovic, Z.; Bonillo, B.; Chitranjan, K.; Price, R. Modelling flow transitions at street junctions with 1D and 2D models. In Proceedings of the 7th International Conference on Hydroinformatics, Nice, France, 4-8 September 2006.

18. Barreto, W.; Vojinovic, Z.; Price, R.; Solomatine, D. A Multi-objective Evolutionary Approach for Rehabilitation of Urban Drainage Systems. Water Resour. Plan. Manag. 2010, 136, 547-554. [CrossRef]

19. Vojinovic, Z.; Sahlu, S.; Seyoum, S.; Sanchez, A.; Matungulu, H.; Kapelan, Z.; Savic, D. Multi-objective rehabilitation of urban drainage systems under uncertainties. J. Hydroinform. 2014, 16, 5. [CrossRef]

20. Martínez, C.; Sanchez, A.; Toloh, B.; Vojinovic, Z. Multi-objective evaluation of urban drainage networks using a 1D/2D flood inundation model. Water Resour. Manag. 2018, 32, 4329-4343. [CrossRef] 
21. Deb, K.; Pratap, A.; Agarwall, A.; Meyarivan, T. A Fast and Elitist Multi-objective Genetic Algorithm. IEEE Trans. Evol. Comput. 2002, 6, 182-197. [CrossRef]

22. Oraei, S.; Saghafian, B.; Shamsai, A. Multi-objective optimisation for combined quality-Quantity urban runoff control. Hydrol. Earth Syst. Sci. 2012, 16, 4531-4542. [CrossRef]

23. Galindo, R.; Martínez, C.; Sanchez, A.; Vojinovic, Z.; Brdjanovic, D. Selecting optimal sustainable drainage design for urban runoff reduction. In Proceedings of the 36th IAHR World Congress Deltas of the Future and What Happens Upstream, The Hague, The Netherlands, 28 June-3 July 2015.

24. Alves, A.; Sanchez, A.; Vojinovic, Z.; Seyoum, S.; Badel, M.; Brdjanovic, D. Evolutionary and holistic assessment of Green-Grey infrastructure for CSO Reduction. Water 2016, 8, 402. [CrossRef]

25. Chichakly, K.; Bowden, W.; Eppstein, M. Minimization of cost, sediment load, and sensitivity to climate change in a watershed management application. Environ. Model. Softw. 2013, 50, 158-168. [CrossRef]

26. Liu, Y.; Theller, L.; Pijanowski, B.; Engel, B. Optimal selection and placement of green infrastructure to reduce impacts of land use change and climate change on hydrology and water quality: An application to the trail creek watershed, Indiana. Sci. Total Environ. 2016, 553, 149-163. [CrossRef] [PubMed]

27. Jayasooriya, V.; Ng, A.; Muthukumaran, S.; Perera, B. Optimal sizing of green infrastructure treatment trains for stormwater management. Water Resour. Manag. 2016, 30, 5407-5420. [CrossRef]

28. Wang, M.; Sweetapple, C.; Fu, G.; Farmani, R.; Butler, D. A framework to support decision making in the selection of sustainable drainage system design alternatives. J. Environ. Manag. 2017, 201, 145-152. [CrossRef] [PubMed]

29. CVC. Corporación Autónoma Regional del Valle del Cauca. Geographic Information System of the Cali-Meléndez-Pance-Aguacatal Catchments; Technical Report (in Spanish). CVC Publishing: Cali, Colombia, 2000.

30. EMCALI. Water Utility of Cali. Sanitation and Management Plan for Discharges; EMCALI Publishing: Cali, Colombia, 2003.

31. DAGMA and Univalle. Identification of Point Sources for the Meléndez and Cañaveralejo Rivers in the City of Cali; Project Report; DAGMA and Univalle Publishing: Cali, Colombia, 2004.

32. Galvis, A.; Bernal, D.P.; Mosquera, P.; Cardona, D.A.; Pinzón, A.L.; Raffey, G. Sustainable Water Improves Tomorrow's Cities 'Health SWITCH Project Study Case: Cali, Colombia. In Proceedings of the 3rd SWITCH Scientific Meeting, Belo Horizonte, Brazil, 30 November-4 December 2008.

33. Galvis, A.; Van der Steen, P.; Gijzen, H. Validation of the three-step strategic approach for improving urban water management and water resource quality improvement. Water 2018, 10, 188. [CrossRef]

34. Shoemaker, L.; Riverson, J.; Alvi, K.; Zhen, J.; Paul, S.; Rafi, T. SUSTAIN-A Framework for Placement of Best Management Practices in Urban Watersheds to Protect Water Quality; EPA Publishing: Washington, DC, USA, 2013.

35. Rossman, L.A.; Huber, W.C. Storm Water Management Model, Reference Manual-Water Quality; USEPA: Cincinnati, OH, USA, 2016.

36. Rossman, L. Storm Water Management Model Reference Manual-Hydraulics; USEPA: Cincinnati, OH, USA, 2017.

37. Martínez, C.; Galvis, A.; Alvis, F.; Werner, M. Model integration to improve an early warning system for pollution control of the Cauca river, Colombia. In Proceedings of the International Conference on Hydroinformatics, New York, NY, USA, 17-21 August 2014.

38. Alvis, F.; Martínez, C.; Galvis, A. A simple regionalisation approach as an alternative to obtain rainfall data in a tropical and ungauged catchment. Ing. Compet. 2016, 18, 34-45.

39. BCC. Bank of the Republic Colombia. 2014. Available online: http://www.banrep.gov.co/ (accessed on 14 March 2018).

40. GVC. Governance of Valle del Cauca 2014. Available online: http:/ / www.valledelcauca.gov.co (accessed on 11 September 2017).

41. Mugume, S.; Butler, D. Evaluation of functional resilience in urban drainage and flood management systems using a global analysis approach. Urban Water J. 2017, 14, 727-736. [CrossRef]

(C) 2018 by the authors. Licensee MDPI, Basel, Switzerland. This article is an open access article distributed under the terms and conditions of the Creative Commons Attribution (CC BY) license (http:/ / creativecommons.org/licenses/by/4.0/). 